\title{
CENTRALIZAÇÃO, AVALIAÇÃO INSTITUCIONAL E PARTICIPAÇÃO: O PAPEL DA DOCÊNCIA.
}

Maria Aparecida Sanches Cardoso Neves

Universidade do Oeste Paulista - UNOESTE - Presidente Prudente. E-mail: asanchescardoso@gmail.com

\section{RESUMO}

Este texto pretende enfatizar a ação das políticas de caráter centralizador no comando e controle das ações avaliativas nos Sistemas de Educação Nacional e Paulista que possibilitaram a inserção de práticas impostas aos docentes. A prescrição de currículos e mecanismos avaliativos culminou na ausência de participação docente nos processos decisórios e incidiu sobre a carreira docente. Todavia, a evidência de alguma prática docente emancipatória ainda se apresenta no cotidiano escolar. Das alternativas existentes, para além da participação, emerge a proposta de valorização do trabalho docente e a dimensão política da prática educativa no processo, em perspectiva dialética da sistematização e apropriação dos conhecimentos historicamente produzidos pela humanidade.

Palavras-chave: Avaliação, Centralização, Participação, Emancipação, Humanização.

\section{INTRODUÇÃO}

O presente trabalho enfatiza as conclusões levantadas em pesquisa qualitativa de um estudo de caso (NEVES, 2011) acerca da ação preponderante do docente no processo de socialização e humanização dos alunos, face à realidade hostil que muitos vivenciam. A perspectiva que se apresenta nos espaços educacionais públicos da Educação Básica, com suas origens em um sistema gerencial impregnado de concepções capitalistas mercadológicas, tem contribuído para o desalento docente e enfatizado a necessidade de se pensar em uma participação educativa e política na condução do ensino. Por estas considerações torna-se fundamental conceber a ação docente fortalecida em processo dialético de interação. Assim, a proposta aqui apresentada objetiva contribuir com a discussão da urgência da emancipação docente concebida na sua ação essencialmente participativa ensejada em movimentos dialéticos de construção do conhecimento.

\section{I- O Sistema Educacional Brasileiro e as políticas educacionais centralizadoras.}

A definição de um Sistema de Educação, como a supõe Cury (2010, p. 164) em um regime de federalismo político e cooperativo, é uma rede de órgãos, instituições escolares e estabelecimentos; um ordenamento jurídico com leis (normas); finalidade comum e base comum. 
Estas características dão sentido a um sistema que possibilita a inserção de políticas educacionais centralizadoras, a exemplo da política de avaliação em larga escala no país.

No estado de São Paulo, o modelo de avaliação em larga escala foi instituído pela Secretaria de Estado da Educação em 1996, quando se pretendia monitorar a qualidade de ensino, subsidiar as tomadas de decisões da Secretaria quanto às políticas educacionais e fornecer informações aos técnicos e educadores. Neste caminho, no ano de 2000, a avaliação estadual objetivou as informações para a tomada de decisões nos vários níveis do sistema; em 2002 ela se estendeu à análise das habilidades de alunos como subsídio para formular e avaliar programas; para o ano de 2003, o propósito enfatizado era promover a cultura avaliativa e, em 2005, discutiase a obtenção de indicadores para a intervenção (FREIRE, 2008).

A partir de 2007, o Sistema de Avaliação de Rendimento do Estado de São Paulo passou a ser articulado aos exames nacionais, por meio de matrizes curriculares para a incorporação do Sistema de Avaliação da Educação Básica (SAEB) e Prova Brasil, o qual utiliza o método estatístico denominado Teoria de Resposta ao Item para a análise do desempenho escolar. Os índices do SARESP são ainda empregados até o presente ano, para o cálculo do Índice de Desenvolvimento da Educação do Estado de São Paulo (IDESP) que se associa às metas de desempenho e ao cálculo de incentivos financeiros aos docentes.

As iniciativas de condução da avaliação, para as tomadas de decisões de gestão de ensino, nos remetem às concepções de centralização das políticas educacionais no Brasil. A avaliação em larga escala adotada em âmbito federal é tida por Oliveira e Sousa (2010, p. 30) como exemplo de o "aspecto mais centralizador das iniciativas de política educacional dos últimos tempos". Uma das principais análises, neste entendimento, aponta para o controle estabelecido à distância, pelos responsáveis pela definição do que será avaliado, sem o possível ônus de eventuais insucessos. Ainda se considera na análise a expectativa presente nesta concepção: "de que a simples divulgação dos resultados obtidos por sistemas e por escolas induza a melhoria de qualidade" (OLIVEIRA; SOUSA, 2010). Assim, o perfil centralizador das políticas educacionais se contrapõe ao sentido de participação nos sistemas educacionais.

A avaliação estadual, desta maneira, vincula-se a um sistema classificatório e prescrito, de modo que os docentes permanecem dependentes da política educacional centralizadora do Sistema de Educação. Os processos de participação e a colaboração dos docentes nos procedimentos decisórios na rede estadual são desarticulados da ação diária da sala de aula. As 
justificativas da tradição do trabalho prescrito aos docentes nos remetem aos resquícios da origem do sistema educacional brasileiro pautada em ações centralizadoras e autoritárias.

Da atuação do Estado, que representa a fonte de suprimentos e de referência normativa para regulação das atividades, depende a concretização do direito da educação. Este direito é estabelecido em normas constitucionais e muitas vezes não é cumprido. Nas razões destacadas para a omissão do Estado na educação, Ghanem (2010, p.192-196) discorre sobre o "caráter autoritário do sistema político e o controle do Estado por parte dos grupos econômicos de interesse". O autoritarismo "é herdeiro da origem colonial do Brasil como Estado/ nação" e atravessou as diferentes fases do sistema político. O equilíbrio da tensão entre Estado e sociedade civil é o que poderia sustentar um sistema político de perfil democrático. $\mathrm{O}$ autor aponta ainda as hipóteses que poderiam explicar a inexistência de participação em educação no Brasil: a repressão, a desinformação e a concepção de educação escolar como ensino (GHANEM, 2010).

A repressão esteve presente no Brasil durante o regime militar e em períodos posteriores. As reivindicações ocorridas durante os movimentos grevistas do magistério nunca demandaram a participação em decisões de política educacional (idem: 202). A desinformação, por sua vez, é caracterizada na composição/finalidade dos conselhos escolares existentes, que embora sejam eleitos, não têm papel político. Resta a hipótese da educação como ensino para justificar a ausência de mobilização de docentes.

Nesse enfoque, o poder burocrático pode se impor também sobre docentes, de modo a reduzir seu trabalho apenas à execução de desígnios originados acima do magistério, num nível superior onde ocorre a concepção do quê e do como ser ensinado. Professores (as) são ao mesmo tempo funcionários (as) de uma organização e profissionais. Uma dessas suas faces requer obedecer, executar. A outra induz a conceber, criar. A educação como ensino tende a reduzir o magistério apenas ao seu aspecto de funcionário (GHANEM, 2010, p. 207).

\section{II- A avaliação como atividade prescrita e o esforço docente.}

Nas atividades docentes observadas no ano de 2011, em pesquisa realizada junto a um grupo docente de uma escola de Educação Básica (NEVES, 2011), constatamos que o desempenho escolar na avaliação em larga escala era uma preocupação sempre constante na ação diária dos docentes, conduzindo-os aos mecanismos de execução de práticas tais como a utilização de cadernos encaminhados pela Secretaria do Estado da Educação, com a prescrição de listagem das supostas habilidades e competências a serem desenvolvidas pelos alunos e trabalhadas pelos 
docentes. Outras práticas desenvolvidas remetiam às repetições de simulados e outros exercícios de fixação de atividades executadas como modelo já observado nas avaliações anteriores.

O movimento articulado para o desenvolvimento de ações cooperativas era perceptível na atuação dos docentes na escola, todavia, a participação política era pouco evidente, salvo na atuação de alguns docentes que desempenhavam outras funções de vereança e ou que de alguma outra maneira estavam envolvidos em atividades locais. Alguma independência do currículo prescrito, no entanto, se observava na ação de alguns docentes ao proporem atividades pensadas como formativas. Houve também depoimentos que culminaram na intenção de alternativas de preservação do direito à educação pelos alunos. Neste sentido, ao propor a educação como ensino, os professores defendiam uma prática de caráter emancipatório:

[...] Na sala de aula, os alunos, não é? Eu acho que os alunos. Os nossos alunos aí, oriundos de uma classe menos favorecida, na grande parte, eles se dedicam e querem superar, infelizmente não são todos, não é, mas nós temos aí, grandes

alunos. ... E assim, quais seriam seus objetivos como educador?

Transformar este aluno menos favorecido em um cidadão, que ele tenha perspectiva de vida. Eu creio que este é um grande fundamento. Fazer com que

este aluno menos favorecido... ele adentre a uma escola pública e que saia dela

com perspectiva de concorrência em igualdade com os demais (PROFESSOR).

Esta direção, no entanto, é de caráter transgressor e de resistência (o que requer um grande esforço do docente) frente ao trabalho em um contexto que se apresenta precarizado e que proporciona a desqualificação e a perda de identidade docente. Os professores que participaram da pesquisa sentiam os efeitos de um cotidiano carregado por instabilidades emocionais: um apresentava-se cansado, o outro frequentemente licenciava-se por apresentar um adoecimento crônico, dois dos demais tinham problemas de saúde na família e careciam de acompanhamento médico também em face às dificuldades em conciliar os afazeres diversos e a rotina de trabalho.

Oliveira (2004, p. 11321- 1132) identifica nas reformas educacionais "sob o argumento da organização sistêmica, da garantia da suposta universalidade, possibilitando baixar custos ou redefinir gastos e permitir o controle central das políticas implementadas", a tendência da retirada da autonomia docente, "entendida como condição de participar da concepção de seu trabalho". Assim, a proletarização técnica e ideológica na docência são decorrentes da perda de controle 
sobre o processo e produto do trabalho e da expropriação de valores a partir desta perda (RODRIGUES, 2002 apud Oliveira, 2004).

Motta (2003, p.369) assegura que a participação pressupõe o ato de participar do poder, o que significa influenciar o poder. No regime federativo, no entanto, onde os sistemas instituídos são de entes federados autônomos e as decisões culminam no embate centralizaçãodescentralização, a partilha do poder carece de extensas discussões e permite a dificuldade de conciliar interesses dado comportamentos de jogo defensivo e não cooperativo, e a tentativa de coordenação (ABRUCIO, 2010).

A influência sobre o poder, todavia, requer mais do que a participação, ela implica na luta pelo desenvolvimento de movimentos emancipatórios que se dão no engajamento das forças coletivas ao rumo almejado. Neste entendimento, a ação participativa docente requer mobilização de maneira que conduza a uma identidade coletiva.

Apesar das condições materiais e objetivas desfavoráveis ao exercício da docência de forma digna, é possível, no nosso entender, constituirmos uma identidade coletiva emancipatória. Isto equivale a dizer que compete a nós pesquisadores e docentes resgatarmos um papel bem mais dignificado do que este que vem sendo outorgado a nós. Devemos fazer nossa própria história, mesmo porque esta "lição de casa" ninguém poderá fazer por nós. (SILVA; HELOANI, 2009, p.223)

\section{III- A ação educativa fundamentada em processos emancipatórios.}

Recorrente destas interpretações a ação educativa deve ser fundamentada em ações que conduzam à autonomia e independência humanas. O trabalho educativo requer a consecução de suas finalidades fundamentadas em assimilações que conduzam à apropriação dos conhecimentos produzidos pela humanidade e a caracterização da humanização em face aos modelos prescritos de trabalho investidos na mercantilização e na ideologia de mercado (SGUISSARD, SILVA JR, SILVA, 2010, p. 12) que tem sustentado a educação brasileira nas últimas décadas.

Duarte (s/d, p 11-12) analisa o trabalho educativo que supõe posicionar-se em relação às objetivações produzidas historicamente; o que requer também um posicionamento acerca do processo de humanização dos indivíduos. Neste entendimento o autor estabelece que a concepção historicizadora da cultura se situa sobre as conquistas mais significativas e duradouras para a humanidade; bem como uma concepção historicizadora da individualidade humana pressupõe maior socialização, "para estabelecer a crítica às condições concretas da vida dos indivíduos e estabelecer diretrizes para o processo educativo desses indivíduos." 
A concepção do trabalho educativo para Duarte (s/d, p13, 15; SAVIANI, DUARTE, 2012) fundamentado por Saviani tem como suposto a formação do indivíduo como gênero humano, para além da divisão social. Importa a apropriação daquilo que é a "transmissão-assimilação do conhecimento objetivo e universal", portanto o trabalho educativo é uma "produção direta e intencional." Assim, a produção é direta em dois sentidos: na relação direta entre professor e aluno e na humanização humana. Neste entendimento há o desenvolvimento do ser humano em um processo intencionalmente dirigido (SAVIANI, 1986; SAVIANI, DUARTE, 2012).

Duarte (s/d, p 16) finaliza seus argumentos propondo, que a partir de suas pesquisas recentes, a hipótese da questão central da pedagogia residiria nas relações que professores e alunos estabelecem com os produtos intelectuais da prática social humana em sua totalidade. Ao apreender a educação (SAVIANI, DUARTE, 2012, p 34) a pedagogia tem "condições de assumir a perspectiva ontológica", o "processo de formação humana" e o percurso de "apropriação das objetivações produzidas ao longo da história".

A pedagogia histórico- crítica (SAVIANI, 2012, p79, 80) considera os educandos como seres concretos na unidade e na diversidade sintetizam as relações sociais "que não escolheram", mas que, no entanto, são inseridos numa sociedade que exige um conhecimento sistematizado produzido historicamente e um currículo pertinente ao contexto atual. Assim, o caminho para a educação e formação humana requer a "ultrapassagem da lógica formal e o manejo do método dialético" (SAVIANI, 2012, p 127).

\section{CONCLUSÃO}

Em decorrência dos pressupostos, a participação e o resgate do papel docente são concebidos como de suma importância. A ação docente possibilita a socialização (NEVES, 2011) e a apropriação dos conhecimentos sistematizados historicamente a cada um de seus educandos para efetivamente se concretizar o processo de humanização.

Saviani (1986, p. 83) explica que "cada professor tem uma contribuição específica a dar em vista da democratização da sociedade brasileira" ao instrumentalizar e ou contribuir "nas ferramentas de caráter histórico, matemático, científico, literário, etc., que o professor seja capaz de colocar em posse do aluno". Assim, cada professor poderá compreender os vínculos de sua docência com a prática social e global. Desse pressuposto decorre a dimensão política da prática educativa que concorre com a prática política inscrita na essência capitalista (idem: 88-90). 0 processo educativo fundado em princípios emancipatórios estabelece a formação humana e 
liberta a docência de funções elementares e subalternas. As reflexões decorrentes das análises de Saviani culminam na importância da superação da sociedade de classes onde o Estado será identificado com a sociedade civil "a qual absorve a sociedade política":

Quer dizer, superada a sociedade de classes, chegado o momento histórico em que prevalecem os interesses comuns, a dominação cede lugar à hegemonia, a coerção à persuasão, a repressão se desfaz, prevalecendo a compreensão. Aí, sim, estarão dadas historicamente as condições para o pleno exercício da prática educativa. (SAVIANI, 1986, p. 90).

\section{REFERÊNCIAS}

ABRUCIO, F. L. A dinâmica federativa da educação brasileira: diagnóstico e propostas de aperfeiçoamento. In: Educação e Federalismo no Brasil: combater as desigualdades, garantir a diversidade. Brasília, Mar 2010- UNESCO

CURY, C. R. J. A questão federativa e a educação escolar. In: Educação e Federalismo no Brasil: combater as desigualdades, garantir a diversidade. Brasília, Mar 2010- UNESCO

DUARTE, N. LUKÁCS E SAVIANI: A Ontologia do ser social e a pedagogia histórico- crítica. Acessado em 30 de Julho de 2013http://www.histedbr.fae.unicamp.br/acer histedbr/seminario/seminario8/ files/GINNNi3M.pdf

FREIRE, L. R. S. C. Saresp 2005: as vicissitudes da avaliação em uma escola da rede estadual. 2008. 118 f. Dissertação (Mestrado) / Faculdade de Educação da Universidade de São Paulo USP. São Paulo.

GHANEM, E. Participação e regime de colaboração entre unidades federadas na educação brasileira. In: Educação e Federalismo no Brasil: combater as desigualdades, garantir a diversidade. Brasília, Mar 2010- UNESCO

MOTTA, F.C.P. Administração e Participação: reflexões para a educação. Educação e Pesquisa. São Paulo, v. 29, n. 2. p. 369-373. Jul/dez. 2003- USP.

NEVES, M. A. S. C. Práticas Educativas de Relevância no Processo de ensino e Aprendizagem em Escolas Públicas. Dissertação de Mestrado. UNOESTE- Presidente Prudente, 2011.

OLIVEIRA, D. A. A restruturação do Trabalho Docente: Precarização e flexibilização. Educação e Sociedade. Campinas, vol 25, no 89, p. 1127-1144, Set-Dez. 2004.

OLIVEIRA, R. P.; SOUSA, Z. S. Introdução- In Educação e Federalismo no Brasil: combater as desigualdades, garantir a diversidade. Brasília, Mar 2010- UNESCO.

SAVIANI, D., DUARTE, N. A formação Humana na perspectiva Histórico-Ontológica. Pedagogia Histórico- crítica e luta de classes na educação escolar. Autores Associados, 2012.

SAVIANI, D. Marxismo, Educação e Pedagogia. Pedagogia Histórico- crítica e luta de classes na educação escolar. Autores Associados, 2012. 
SAVIANI, D. Debates sobre a Educação, Formação Humana e Ontologia a partir da questão do método. Pedagogia Histórico- crítica e luta de classes na educação escolar. Autores Associados, 2012.

SAVIANI, D. Escola e Democracia. São Paulo, Cortez Editora/autores associados. 12ª edição, 1986.

SILVA JR; SGUISSARD V, SILVA E. , Trabalho Intensifcado na Universidade pública Brasileira, Universidade e Sociedade, DF, no 45, 2010.

SILVA, E. P.; HELOANI R., Gestão Educacional e trabalho docente: aspectos socioinstitucionais e psicossociais dos processos de saúde doença, Revista HISTEDBR On-line, Campinas, n.33, p.207227, mar.2009 - ISSN: 1676-25. 